\title{
First results from imaging riometer installed at Indian Antarctic station Maitri
}

\author{
Jayanta K Behera ${ }^{1, *}$, A K Sinha ${ }^{1}$, Anand K Singh ${ }^{2}$, Rahul Rawat ${ }^{1}$, Geeta Vichare ${ }^{1}$, \\ Ajay Dhar ${ }^{1}$, B M Pathan ${ }^{1}, \mathrm{~K}_{\mathrm{U}} \mathrm{NaIR}^{3}$, C Selvaraj ${ }^{3}$ and P Elango ${ }^{3}$ \\ ${ }^{1}$ Indian Institute of Geomagnetism, New Panvel (W), Navi Mumbai 410 218, India. \\ ${ }^{2}$ National Centre for Antarctica and Ocean Research, Headland Sada, Vasco-da-Gama, Goa 403 804, India. \\ ${ }^{3}$ Equatorial Geophysical Research Laboratory, VittalapuramVilakku, Krishnapuram, Maharajanagar, \\ Tirunelveli 627 011, India. \\ *Corresponding author.e-mail: jayanta.sssj@gmail.com
}

Cosmic noise absorption (CNA) measurred by imaging riometer, is an excellent tool to passively study the high latitude D-region ionospheric conditions and dynamics. An imaging riometer has been installed at Indian Antarctic station Maitri (geographic $70.75^{\circ} \mathrm{S}, 11.75^{\circ} \mathrm{E}$; corrected geomagnetic $63.11^{\circ} \mathrm{S}, 53.59^{\circ} \mathrm{E}$ ) in February 2010. This is the first paper using the imaging riometer data from Maitri. The present paper introduces the details of this facility, including its instrumentation, related CNA theory and its applications. Sidereal shift of around 2 hours in the diurnal pattern validates the data obtained from the newly installed instrument. Moreover, the strength of cosmic noise signal on quiet days also varies with months. This is apparently due to solar ionization of D-region ionosphere causing enhanced electron density where collision frequency is already high. The main objective of installing the imaging riometer at Maitri is to study magneotspheric-ionospheric coupling during substorm processes. In the current study, we present two typical examples of disturbed time CNA associated with storm-time and non-storm time substorm. Results reveal that CNA is more pronounced during storm-time substorm as compared to nonstorm-time substorm. The level of CNA strongly depends upon the strengthening of convectional electric field and the duration of southward turning of interplanetary magnetic field before the substorm onset.

\section{Introduction}

Earth's ionosphere plays a vital role in the medium frequency $(\mathrm{MF})$ and high frequencies $(\mathrm{HF})$ radio communication (Little and Leinbach 1959). Radio waves transmitted from the Earth are reflected from the ionosphere and travel long distances, which provide a mode for communication. However, ionospheric absorption of radio waves is often the controlling factor for $\mathrm{MF}$ and $\mathrm{HF}$ radio communications. This is particularly important at high latitudes, where ionospheric storms frequently result in unreliable communications (e.g., Rourke 1961). The polar blackout phase or, periods of complete absorption of MF and $\mathrm{HF}$ radio signals due to ionospheric storms may last for many hours, and over a period of a month. In addition to that, it may also reduce the signal in-time by more than $20 \%$ (Detrick and Rosenberg 1990).

Studies of ionospheric absorption of radio waves are thus of considerable interest to the communication engineers and space researchers. So requirement of an instrument to monitor the lower ionosphere is unavoidable. The wide beam riometer has been used for this purpose since 1950s. Basically, riometer is the acronym of Relative Ionospheric

Keywords. Imaging riometer; cosmic noise absorption; magnetospheric substorm; geomagnetic storm; auroral electrojet. 
Opacity Meter using Extra Terrestrial Electromagnetic Radiation. It is an important ionospheric diagnostic tool which uses the randomly fluctuating, almost 'white', noise from galactic radio sources as probing signals to investigate the upper, ionized part of the Earth's atmosphere (Little 1954; Little and Leinbach 1958, 1959). Outside the influence of the Earth's environment these radio signals have fairly constant intensities (Stauning 1994). Absorption of the cosmic radio signal is experienced due the ionosphere at frequencies above $15 \mathrm{MHz}$ when highly directional antennas are pointed towards a particular part of the sky. Celestial objects like Quasars, super dense objects that lie far from Earth, emit electromagnetic waves in Earth's entire spectrum including radio waves.

For last two decades, use of imaging riometer for high latitude ionospheric study has been quite popular among polar researchers (e.g., Detrick and Rosenberg 1990; Hargreaves et al. 1991). Important studies have been carried out using riometer data to probe the ionospheric conditions in addition to their relation with space weather events. The first detailed paper by Ansari (1964) showed simultaneity of occurrences of radio wave absorption and visual aurora which is a manifestation of energetic solar wind particles precipitation into the high lattitude ionosphere. At high latitudes, two main types of absorption events are seen in riometer measurements: (1) the auroral absorption (AA), caused by precipitating magnetospheric electrons and (2) polar cap absorption (PCA), caused by flare-associated solar energetic ions. Magnetospheric particles in the $0.5-20 \mathrm{keV}$ energy range precipitating in the ionospheric E- and F-regions are mostly responsible for the visual aurora, which are extensively studied with ground- and satellite-based optical instruments. (e.g., Frey et al. 2004; Kellerman 2009). More energetic electrons $(>20 \mathrm{keV})$ enhance the electron densities in the lower E- and D-regions $(<100 \mathrm{~km})$ of ionosphere. Walker and Bhatnagar (1989) confirmed experimentally that auroral absorption and electrical conductances are closely related. Moreover, CNA depends indirectly on the electric field. These characteristics are observed when strong electric fields drive plasma waves that in turn interact with electrons increasing their temperatures and effective collision frequencies (Schlegel and St-Maurice 1981; St-Maurice et al. 1981).

\subsection{Indian perspective of ionospheric study using cosmic noise study}

Indian contribution to the study of cosmic noise started six decades ago. Mitra and Shain (1953) introduced cosmic noise method for the first time.
The ionospheric absorption was measured by comparing the signal strength of extraterrestrial radio waves received on a fixed receiving system with the signal strength received on the same system at the same sidereal time under conditions of negligible ionospheric absorption. Bhonsle and Ramanathan (1958) reported absorption in the D-region over Ahmedabad, India (geographic: $23.02^{\circ} \mathrm{N}, 72.38^{\circ} \mathrm{E}$ ) by using riometer at $25 \mathrm{MHz}$. Occurrence characteristic of ionospheric absorption in the time period from afternoon to evening is consistent with the daily variation of the ionospheric F-region absorption associated with increases of foF2 which were obtained from the statistical analysis of the riometer absorption on $25 \mathrm{MHz}$ at Ahmedabad in India (Abdu et al. 1967). Diurnal and seasonal variation of total ionospheric absorption (L) at an equatorial station, Trivandrum (dip 0.6 S, geographic long. $\left.76.56^{\circ} \mathrm{E}\right)$ has been studied using two years riometer data (Parameswaran and Krishnamurthy 1976). They have investigated the dependence of $L$ on geophysical parameters and sunspot numbers. In addition to that, they have estimated the electron tempearature of F-region from the F-region contribution to the total absorption. Lunetta and Abdu (1971) suggested that the absorption of cosmic radio noise varies with the latitude of the observations.

\subsection{Advantages and essential features of an imaging riometer}

Advantages of imaging riometer over simple riometers are quite significant. Basically wide-beam riometers consist of simple antenna array system with an azimuthally symmetric radiation pattern. So, they have wide field of view (FOV) but no imaging capability. The antenna is connected to a receiving device which measures the power of the incoming 'signal' (cosmic background noise). In the absence of geomagnetic activity the received power forms a baseline, or 'quiet day curve' from which absorption measurements can be derived. They are useful for a general overview of the current state of the ionosphere, but do not provide any information on the spatial structure and dynamics within their field of view. An imaging riometer consists of dipole antennae configured as filled phased array (Mailloux 2005) and a modified two dimessional Butler matrix (Butler and Lowe 1961). Hence it can produce multiple imaging beam with better resolution. High energetic particle precipitation and their spatial and dynamic structure can be studied using imaging riometer.

Cosmic noises received by imaging riomter are in the radio wave frequency range well above $15 \mathrm{MHz}$ (Mitra and Shain 1953). These radio waves 
propagate continuously towards the Earth. While coming in, noises have to propagate through the height integrated ionosphere. During geomagnetic disturbed time, these radio waves undergo attenuation due to enhanced ionization and collision frequency in the ionosphere. Sen-Wyller formalism (Sen and Wyller 1960) provides the most complete theoretical treatment for the propagation and attenuation of radio waves. However, the typical frequency at which the riometer operates, is much higher than the plasma frequency, so AppletonHartee formulae are good approximations and provide a well established relation among the various ionospheric parameters such as collision frequency, gyro-frequency, etc., with radio wave absorption in dB.

The typical absorption formula is:

$$
A(d B)=4.6 \times 10^{-5} \int \frac{N_{e} \nu \cdot d l}{\nu^{2}+\left(\omega \pm \omega_{H} \cos \theta\right)^{2}},
$$

where $N_{e}$ and $\nu$ are respectively the local electron density and collision frequency, $\omega_{H}$ is the electrongyro frequency. The + and - signs indicate the two different types of polarization of the incoming wave. $\omega$ is the angular frequency of the wave propagating at an angle $\theta$ with the geomagnetic field along the path $l$ of which $d l$ is the small element.

The effective electron collision frequency can be derived with the use of Maxwellian distribution function and can be written as (Aggrawal et al. 1979):

$$
\nu_{\text {eff }}=\frac{\int_{\nu=0}^{\infty} \sum_{n=1}^{N} \sigma_{m}^{n}(v) v F(v) d v}{\int_{v=0}^{\infty} F(v) d v},
$$

where $\sigma_{m}^{n}$ is the velocity dependent cross-section for momentum transfer during electron collisions with species $n$ (electrons or ions).

\subsection{Installation of imaging riometer at Maitri}

The first imaging riometer system (with 49 beams) was installed at South Pole station in Antarctica in 1988 by the University of Maryland group (Detrick and Rosenberg 1990). Then just after six years, there were around six additional imaging riometer installations with varying beam dimension from $8 \times 8$ or $4 \times 4$ beams. A state-of-the-art $38.2 \mathrm{MHz}$ imaging riometer was installed at Maitri during the austral summer of 2009-2010. The system consists of $16(4 \times 4)$ crossed dipole antennae that can be upgraded to $64(8 \times 8)$ system at a later stage. The field of view (figure 1 ) of this system at $90 \mathrm{~km}$ altitude is $200 \times 200 \mathrm{~km}$ with time resolution of 1 second. The operation of the riometer is mainly controlled by the advanced riometer

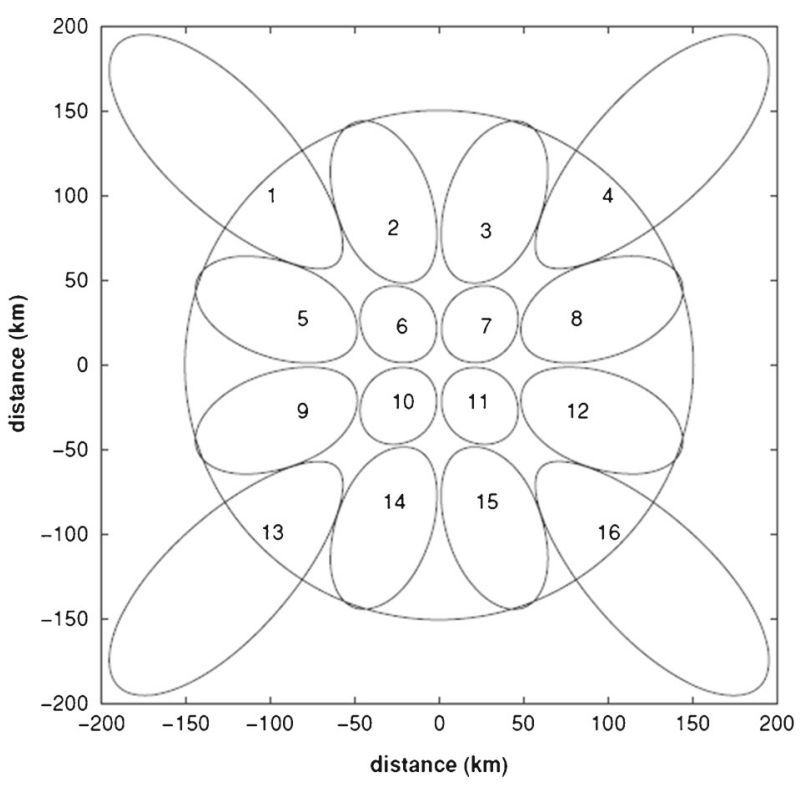

Figure 1. Riometer beam projection for Maitri, Indian Antarctic station with $4 \times 4$ field array. The $-3 \mathrm{~dB}$ beams are projected in the lower ionosphere at a height of $90 \mathrm{~km}$. The larger circle represents the wide beam field of view. The smaller lobe kind structures represent the 16 imaging beams field of view.

component (ARCOM) software provided by Lancaster University, UK, which is solely responsible for starting and stopping of data recording, selection of files, etc. The complete analysis, starting from the generation of standard quiet day curve (QDC), the checking of validation to the absorption plot, keogram as per the demand, can be controlled by a software called Multi Instrumental Analysis (MIA), which is developed by manufacturer at Lancaster University, UK (Honary et al. 2011).

Generally, the imaging riometer system uses an array of ' $N^{2}$, where $N=2^{m}(m=1,2,3$, $4, \ldots$ ) identical antenna elements, such as simple or crossed dipoles, placed in a square grid over a common ground plane. Typically, the separation of elements would be $0.5 \lambda$, where $\lambda$ is the wavelength, while their heights above the ground plane would be $0.25 \lambda$. The $N^{2}$ antenna elements are coupled via cables of identical electrical lengths to a so-called Butler matrix (Butler and Lowe 1961). The beam-forming Butler matrix consists of power divider, adder hybrids, and phase shift elements. It divides and combines the signals from the $N^{2}$ inputs to the $N^{2}$ outputs, such that all input terminals are connected to each output terminal with systematically varying phase shifts. For a given geometry of the antenna array, the phase shifts at each output terminal adds to the phase of the signals arriving from a specific direction in space. The $N^{2}$ output terminals are connected to riometer channels, where each riometer channel acts as an 
ordinary riometer receiver. In most applications the channels are grouped, and commutated within each group, in order to reduce the number of riometer instruments required.

\section{Instruments and datasets}

For the present study, we have used both multiinstrumental datasets. For CNA observations, we have taken data of imaging riometer, which was installed at Maitri during austral summer of 2009-2010. The stability and correctness of data obtained from imaging riometer has been tested and this is the first publication utilizing this new dataset obtained from Indian facility available at Maitri. In addition to imaging riometer, we have used magnetic field data. Indian Institute of Geomagnetism has been operating a digital fluxgate magnetometer (DFM) at Indian Antarctica station, Maitri since 2003. The magnetic field components at Maitri sampled at 1-s intervals have been used in this study.

In addition to that, datasets were taken from World Data Centre (WDC), Kyoto (http://wdc. kugi.kyoto-u.ac.jp/) for auroral electrojet (AE) index and symmetric-H (SYM-H) index. Interplanetary magnetic field (IMF) and solar wind data such as solar wind velocity, recorded by instruments aboard ACE satellite were made available by CDAWeb (http://cdaweb.gsfc.nasa.gov/).

\subsection{Technique for deriving $Q D C$}

The method of determining QDC of cosmic noise signal has been discussed extensively by several authors (e.g., Mitra and Shain 1953; Lusignan 1960; Steiger and Warmick 1961; Armstrong et al. 1977; Krishnaswamy et al. 1985; Tanaka et al. 2007). Recently, Moro et al. (2012) have presented new modified technique for Riometer Network (SARINET) data from South America with respect to method of Tanaka et al. (2007). In that paper, two criteria have been followed: (1) riometer data selection according to the geomagnetic activity and (2) data cleaning with respect to electromagnetic interference as well as some other noises.

In the current approach for deriving QDC of cosmic noise signal, we have used two criteria as followed by Moro et al. (2012). For fulfillment of the first criterion, the average of imaging riometer data for the five international quietest days was used to derive QDC for a particular month. Table 1 shows the list of days taken in a month during the year 2010-2011 for deriving QDC. It should be noted that only 6 days data were available during December 2010, out of that, only one day was magnetically quiet $\left(\mathrm{K}_{p}<3\right)$. The second set of
Table 1. List of number of quiet days considered for $Q D C$ analysis of cosmic noise signal. Continuous 12 months period of imaging riometer data have been taken from November 2010 to October 2011. This period is taken as per the data availability and quality.

\begin{tabular}{llc}
\hline Year & Months & No. of days \\
\hline 2010 & November & 4 \\
& December & 1 \\
& January & 4 \\
& February & 5 \\
& March & 5 \\
& April & 5 \\
& May & 5 \\
& June & 5 \\
& July & 4 \\
& August & 5 \\
& September & 5 \\
& October & 5 \\
\hline
\end{tabular}

criteria are taken for removing electromagnetic interference. This may be produced due to presence of man-made interference, thunderstorms or solar noise bursts. These bursts can affect the estimation of the QDC leading to an increase of the QDC level (Moro et al. 2012). Here, we have taken the selected days for the year 2010 and 2011 confining to quietest days of month. The error limit of QDC curve ranges from 0.02 to $0.30 \mathrm{~dB}$. The maximum error value has been recorded in January month and minimum in the September month. Since imaging riometer can serve both the narrow beam application as well as wide beam application, we have chosen the solar zenith corrected wide beam data for this study. The imaging riometer dataset has inbuilt provision to differentiate wide beams and narrow beams. In figure 2, QDC of each month has been plotted.

\subsection{Sidereal time and monthly variation of QDC at Maitri, Antarctica}

The signal strength of radio noises, coming from the interstellar space varies with sidereal time (time scale based on earth's rate of rotation measured relatively to fixed stars) and months. In general, average sidereal day is of $23 \mathrm{hr} 56 \mathrm{~min}$ and $4 \mathrm{~s}$ whereas the solar day is of $24 \mathrm{hrs}$. So there is an approximate 4 minute difference between sidereal and solar day. Imaging riometer data is in solar time format. While deriving QDC, with respect to solar time, we would expect a shift of about $2 \mathrm{hr}$ (30 days $\times 4 \mathrm{~min})$ in the diurnal pattern of signal strength between consecutive months. This seems to be a genuine tool to assess the accuracy as well as the correctness of data and thereby validate the new dataset. 


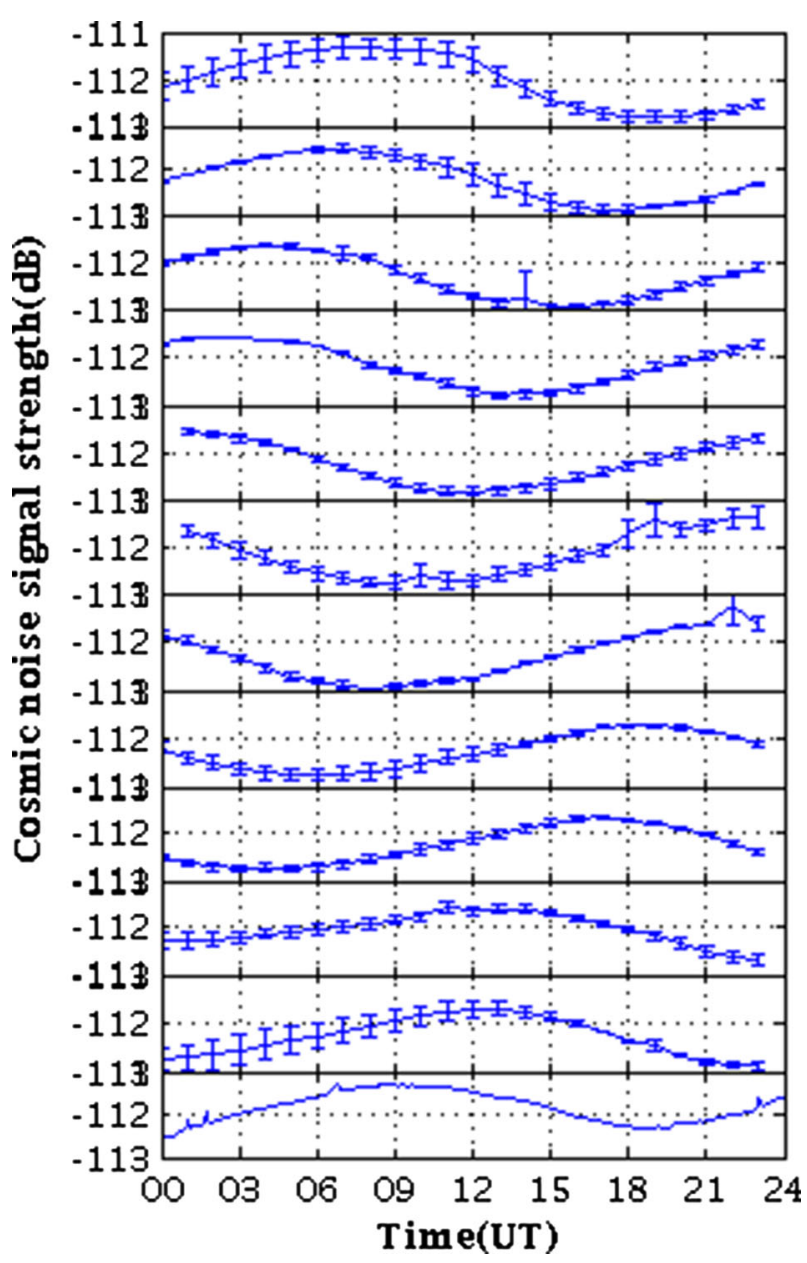

Figure 2. Quiet day cosmic noise signals or quiet day curves (QDCs) for each month of the year 2010-2011. Here wide beam (beam 17) data of imaging riometer was used for deriving QDCs.
We observed an approximate shift of around $2 \mathrm{hr}$ in the consecutive months that can be seen in figure 3. In January, the maximum value of the signal strength has been obtained at around $0900 \mathrm{UT}$, whereas in February, the occurrence time of maximum value has shifted to around 0700 UT. Similarly for other months, the shift of $2 \mathrm{hrs}$ is consistently observed. Moreover, if one follows the red tone which represents the maximum strength of QDC, around $2 \mathrm{hr} /$ month shift is consistently observed.

In quiet conditions of ionosphere over the station of Maitri, cosmic noise signal has a regular diurnal pattern (figures 2 and 3). However, the Sun can also influence the level of signal through the following mechanism. The ultraviolet rays of the Sun enhances the ionization of the ionosphere which ultimately causes more absorption of signals of cosmic noises even on a quiet day, when there is no additional input of particle flux from the magnetosphere, e.g., during substorm phenomena (Browne et al. 1995). At Antarctica, seasonal variation of strength of quiet day curves of cosmic noises has been observed. Figure 4 shows a seasonal variation of the cosmic noise signal strength. In three panels, average strength, maximum strength and minimum strength of the QDC of cosmic noise signal for each month have been plotted respectively. There is comparatively maximum drop of signal strength (average, maximum and minimum) in the months of March (autumn equinox month) and August (pre-spring equinox month). However, the average strength of cosmic noise signal is maximum $(\sim-112.03 \mathrm{~dB})$ in the month of May,

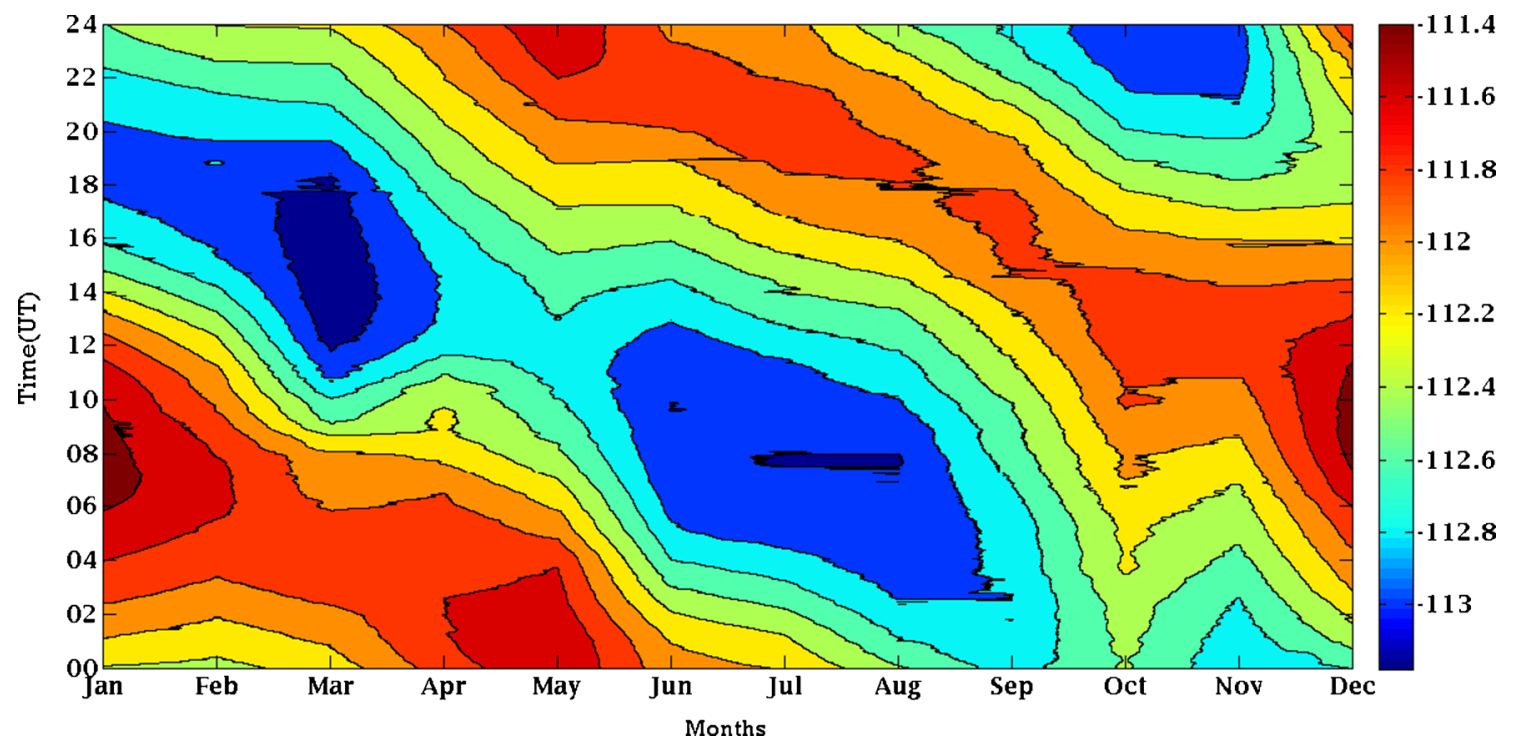

Figure 3. Contour plot for sidereal shift of maximum signal strength of cosmic noise signal for consecutive months. For the month January to May, shift of $\sim 10 \mathrm{~h}(\sim 10$ to $00 \mathrm{UT})$ of maximum signal strength is seen. Similarly, for the month June to December, shift of $\sim 14 \mathrm{~h}(\sim 24$ to $10 \mathrm{UT})$ is seen. 
which is in winter season and $(\sim-111.95 \mathrm{~dB})$ in December month in summer at Antarctica. From equation (1), one would expect higher cosmic noise signal strength during winter (no-Sun) months when ionospheric conductivity is less and opposite for summer (sunlit) months. However, in our observation, we see very complex behaviour of signal strength variation over months (figure 4). When austral winter approaches (March onwards) signal strength rises (as expected), whereas for the rest of the months variations are quite random. For example, sudden drop in signal strength from January to March (summer season), May to June (winter in progress) and relatively constant variation till the commencement of austral summer and further increase cannot be explained on the basis of solar illumination. It makes us believe that other factors significantly contribute towards the seasonal variation of signal strength of QDC.

\section{Observations of CNA during storm-time and non-storm time substorms}

In the present study, we have examined CNA characteristics during storm time substorm and nonstorm substorm occurring near midnight hours at Maitri on 12 April 2011 and 9 July 2011, respectively. We observe that Maitri comes under

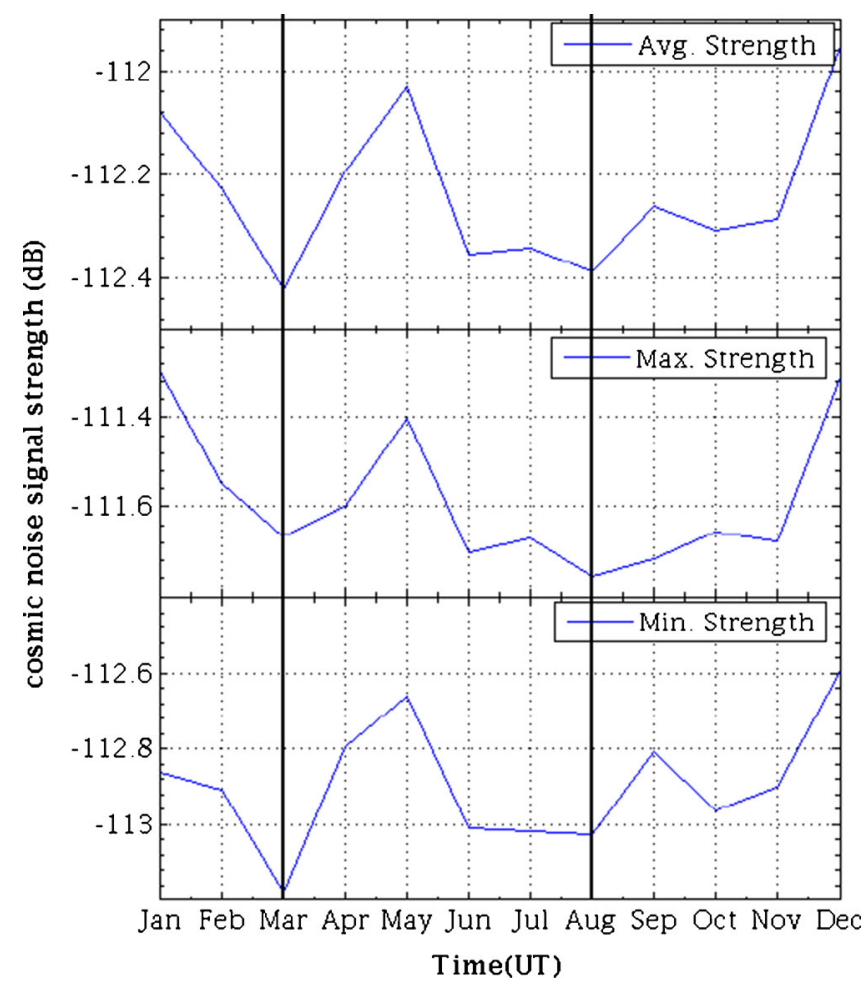

Figure 4. Seasonal variation of cosmic noise signal strength: upper, middle and lower panels are respectively for average, maximum and minimum strength values. the influence of westward electrojet for both the events. However, there is a subtle difference to note between these two events.

\subsection{April 2011 event of CNA during the storm time substorm}

Cosmic noise absorption (CNA), in association with the magnetospheric substorm that occurred during 0600-0800 UT on 12 April 2011 has been shown. For this event Maitri station would lie in 0500-0700 MLT interval as $\mathrm{MLT}=\mathrm{UT}-1$ for our station. In figure 5, we depict the interplanetary magnetic field (IMF) and solar wind velocity as observed by instruments aboard ACE satellite located outside of the Earth's magnetosphere (at $\mathrm{X}=229.6 \operatorname{Re}, \mathrm{Y}=-21.5 \operatorname{Re}, \mathrm{Z}=-40.9 \operatorname{Re}$ in GSM coordinate system: here Re is the radius of the Earth $\sim 6378 \mathrm{~km}$ ). In order to corroborate the interplanetary observations with ground magnetic data, IMF and solar wind data have been delayed

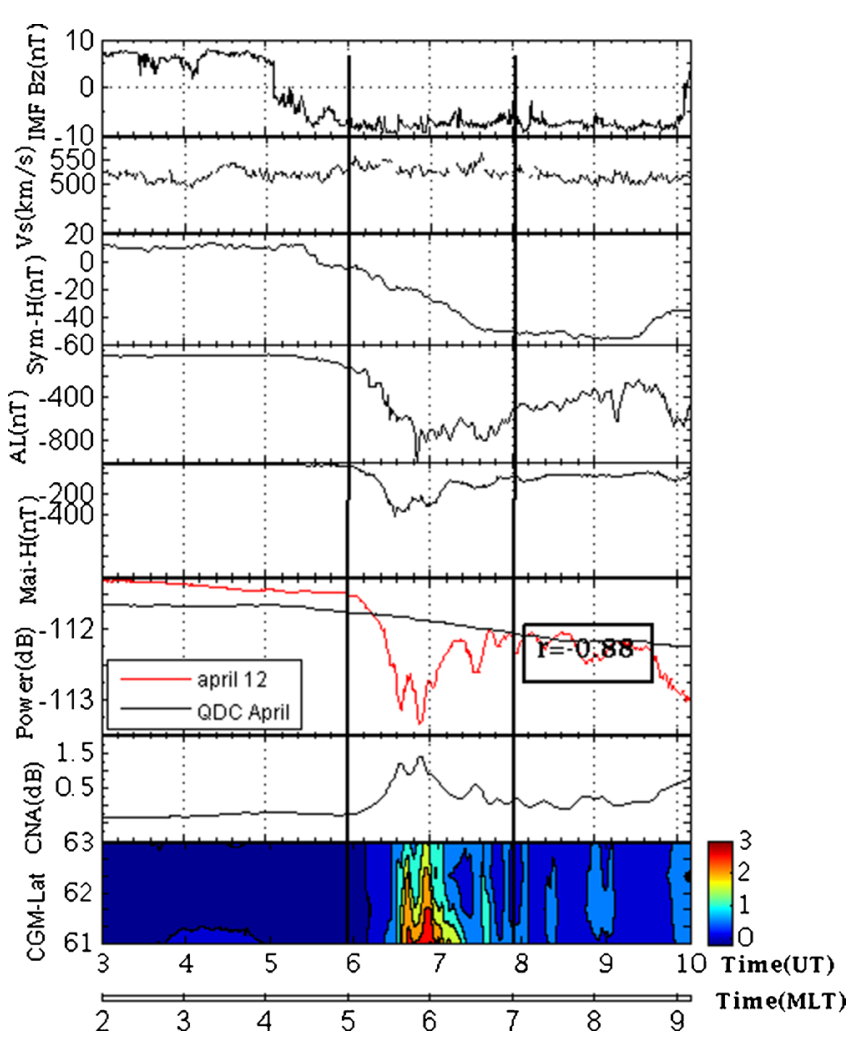

Figure 5. (From top to bottom) Bz component of interplanetary magnetic field (IMF), solar wind velocity $(V s)$ as observed by ACE satellite, Sym-H index, AL index, geomagnetic $\mathrm{H}$-component variation, cosmic noise signal power (red line indicates the signal strength of 12 April 2011, whereas the black line indicates the quiet day signal for the April month), CNA and image of CNA at Maitri station. Interplanetary observations are delayed by $60 \mathrm{~min}$ to compare with the gorund data. This event represents the CNA during storm time-substorm. Correlation coeffiecient between $\mathrm{H}$-componet and CNA in this case is high $(r=-0.88)$. 
by 60 minutes taking into account the travel time of solar wind at an average speed of $\sim 500 \mathrm{~km} / \mathrm{s}$ from the location of the satellite to the magnetopause of the Earth. The upper first two panels represent the IMF Bz and solar wind velocity $(V s)$ respectively. In the next two panels, SYM-H and AL-index have been plotted respectively. The bottom four panels represent the $\mathrm{H}$-component of geomagnetic field, cosmic noise signals, relative CNA and image of CNA over Maitri station. In the sixth panel, quiet day signal of April month and signal of individual day (12 April 2011) have been plotted. We obtained CNA (the bottom-most panel) for the day by taking difference of cosmic noise signal of that day in a month from the QDC of the same month. The bottom-most panel shows the image plot of CNA during the event. It has been observed that CNA becomes more intense during the period of 0630-0730 UT.

The onset of substorm can be clearly seen at $\sim 0600$ UT in the AL-index with a sharp depression of $\sim 1000 \mathrm{nT}$ (figure 5). This appears to be a storm time substorm event as the SYM-H index value has gone down to $-50 \mathrm{nT}$ (Hsu and McPherron 1998). The solar wind velocity on that particular day was high $(\sim 500 \mathrm{~km} / \mathrm{s})$ and steadily increased up to $550 \mathrm{~km} / \mathrm{s}$. The solar wind velocity was steady during all the phases of substorm. The substorm triggering was initiated with sharp southward turn of IMF Bz at $\sim 0500$ UT. It remained southward for $5 \mathrm{hrs}$ then turned northward at 1010 UT approximately. At the onset of substorm, simultaneous occurrence of westward electrojet and CNA has been observed over Matri. Intensity of the westward electrojet is weaker over Maitri ( $\mathrm{H}$ depression $\sim-350 \mathrm{nT}$ ) than what is observed in the AL-index. This could be due to the fact that Maitri station was around $0500 \mathrm{hr}$ MLT and quite away from the center of the westward electrojet which peaks around midnight (Allen and Kroehl 1975; Singh et al. 2012). Moreover, due to the absorption of cosmic radio signal, it was attenuated by more than $1.5 \mathrm{~dB}$ in comparison to monthly QDC (see bottom panel of figure 5). It should be noted that the correlation coefficient $(r)$ between H-component and strength of CNA during the event (05000700 MLT) at Maitri for this event is very high $(r=-0.88)$.

\subsection{July 2011 event of CNA during non-storm time substorm event}

On 9 July 2011, we observed a substorm during 0300-0500 UT which is not accompanied by storm. For this event, Maitri station would be in the postmidnight hour (0200-0400 MLT). Top two panels of figure 6 depict the IMF Bz and solar wind

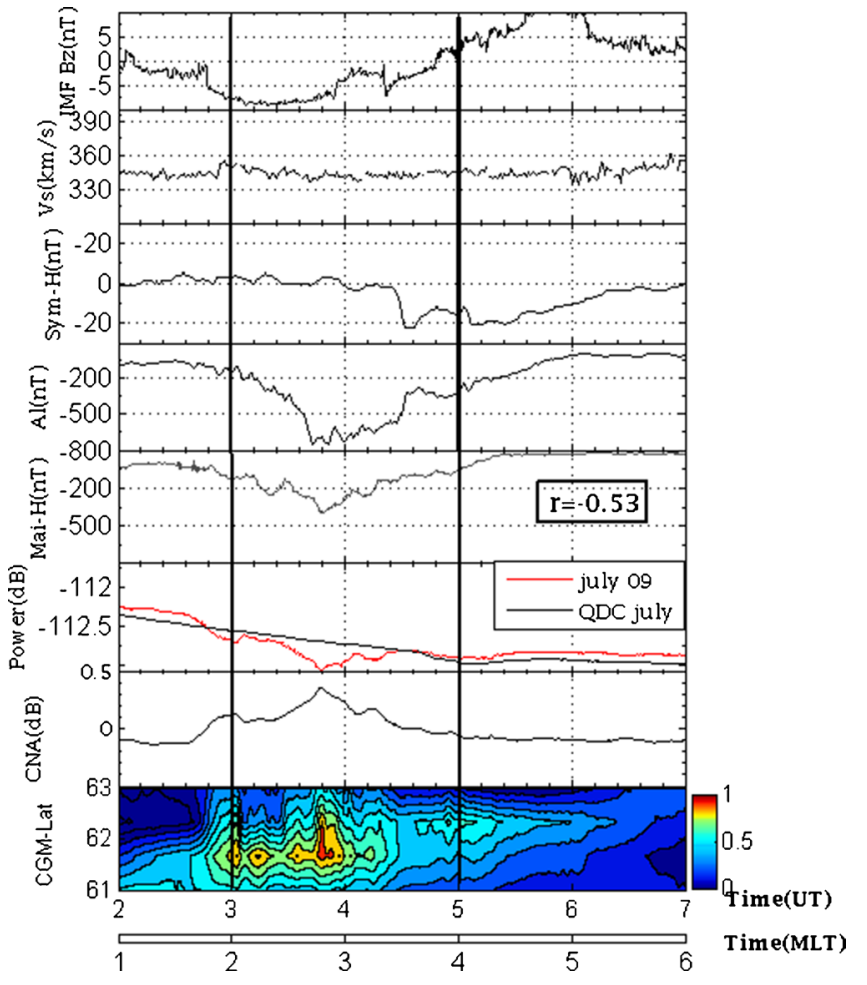

Figure 6. (From top to bottom) Bz component of interplanetary magnetic field (IMF), solar wind velocity $(V s)$ as observed by ACE satellite, Sym-H index, AL index, geomagnetic $\mathrm{H}$-component variation and cosmic noise signal power (red line indicates the signal strength of 9 July 2011, whereas the black line indicates the quiet day signal for the July month), CNA and image of CNA at Maitri station. Interplanetary observations are delayed by $71 \mathrm{~min}$ to compare with the gorund data. This event represents the CNA during non-storm time substorm. Correlation coeffiecient between $\mathrm{H}$-componet and strength of CNA in this case is less $(r=-0.53)$.

velocity $(V s)$ as observed by instruments aboard ACE satellite. During this event the location of $\mathrm{ACE}$ was at $\mathrm{X}=237.9 \operatorname{Re}, \mathrm{Y}=40.4 \mathrm{Re}, \mathrm{Z}=$ 23.0 Re in GSM coordinate system. In order to relate the interplanetary observations with ground magnetic data, IMF and solar wind data have been delayed by 71 min taking into account the travel time of solar wind at an average speed of $\sim 340 \mathrm{~km} / \mathrm{s}$ from the location of the satellite to the magnetopause of the Earth. In the next two panels, SYM-H and AL indices have been plotted respectively. The bottom four panels respectively show $\mathrm{H}-$ component of geomagnetic field, cosmic noise signals, relative CNA and image of CNA at Maitri. In the sixth panel, quiet day signal of July month and signal of 9 July 2011 have been plotted. We obtained CNA (the bottom-most panel) for the day by taking difference of cosmic noise signal of that day in a month from the QDC of the same month. The bottom-most panel shows the image plot of CNA during the event. It has been observed that 
CNA become relatively stronger during a small period of 0340-04310 UT.

Generally, non-storm time substorms have no sign of simultaneous storm (Hsu and McPherron 1998). At the time of onset $(\sim 0300$ UT) of substorm the sym-H index was $\sim 1 \mathrm{nT}$, which clearly shows no signature of enhancement of ring currents. The magnitude of AL-index was $\sim 700 \mathrm{nT}$. Simultaneous observation of solar wind velocity for ACE satellite showed steady and slow flow of solar wind having velocity $\sim 340 \mathrm{~km} / \mathrm{s}$ with southward IMF Bz. This non-storm time substorm led to lesser absorption of cosmic noise $(\sim 0.4 \mathrm{~dB})$ along with almost same magnitude of westward electrojet $(-350 \mathrm{nT})$ despite the fact that AL-index was less $(\sim 700 \mathrm{nT})$ as compared to storm-time substorm of 12 April 2011 seen over Matri station. This is for the reason that Maitri was at around $0200 \mathrm{hr}$ MLT and relatively nearer to the centre of westward electrojet (discussed earlier in the figure 5). The correlation coefficient between $\mathrm{H}$-component and strength of CNA during the event (0200-0400 MLT) at Maitri in this case was found to be less $(r=-0.53)$ as compared to stormtime substorm case of 12 April 2011. However, we obtain better $(r=-0.75)$ when we restrict the calculation of correlation coefficient within the time limit (0200-0330 MLT). This time limit has been taken due to the fact that CNA lasts for this period of time only during the event.

\section{Discussion and conclusion}

For the first time, data of imaging riometer at Maitri, Antarctica have been used to study the substorm activity at Maitri in this work. The observation of CNA using imaging riometer could be a great asset for carrying out the research in subauroral ionosphere. The usefulness of this instrument is remarkable in understanding precipitation dynamics due to substorm processes at subauroral latitude region. In this paper we have given a brief account of the background, theory and instrumentation with an emphasis on validating the newly obtained dataset.

The quiet day curve (QDC) of any new instrument is the most essential part of the study. One has to understand the daily and seasonal variation of QDC of new instrument for further research. So, here we have discussed the sidereal and monthly variation of QDCs. A consistent sidereal shift of $\sim 2$ hrs in each consecutive month has been seen which signifies the consistency and reliability of the new instrument. Thus, the shifting of the main source of the cosmic noise signal with sidereal time can be clearly identified.
Monthly variation of cosmic noise signal in quiet condition, i.e, QDCs not only depends on the source of galactic cosmic noise but also on other factors. It seems other things such as orbital motion of the Earth, the distance of the Sun from the Earth and level of ionization in the D-region during various months, are responsible for cosmic noise during various months have simultaneous impact on the cosmic noise signal variation with months.

And finally, we have shown two different cases of CNA during storm time and non-storm time substorms, both occurring in post-midnight to early morning sector. Magnetic reconnection (e.g., Baker et al. 1996) and dipolarization/current disruption (e.g., Lui et al. 1998) in the near-earth magnetotail have been suggested as the cause of substorm expansion onsets. Initially it was suggested that storm and non-storm time substorms are manifestation of different mechanism, namely magnetic reconnection and current disruption respectively (Baumjohan et al. 1996). But later it was shown that storm and non-storm time substorms do not differ qualitatively in the generation mechanism (Hsu and McPherron 1998). Nevertheless, the energy accumulation and the dipolarization tend to be more significant during storm time substorms.

Maitri is a subauroral station located in Antarctica and it is expected that the auroral oval would expand and cover Maitri location during disturbed days. Hence the station will come under the influence of auroral electrojet. Here, during both the CNA events associated with magnetospheric substorm, the equatorward expansion of auroral oval has taken place. In case of CNA event occurring 12 April 2011 during storm-time substorm, the auroral electrojet was slightly stronger $(\mathrm{AL} \sim 1000 \mathrm{nT})$ as compared with the non-storm time substorm event of 9 July 2011 (AL $700 \mathrm{nT}$ ). During both the substorms, clear influence of westward electrojet of almost the same magnitude $(\sim 350 \mathrm{nT})$ with simultaneous occurrence of CNA was observed over Matri. Maitri was nearer to the onset location of substorm of later case (9 July 2011 - non-storm time) compared to that during 12 April 2011 storm-time, as the MLT range for the event on 9 July 2011 was $2-4$ hrs and it was $5-7$ hrs for 12 April 2011. There are different kinds of CNA events depending on the local time and magnetospheric phenomena (Stauning 1994). However, the above two CNA events which were examined in this study, are confirmed to be associated with substorms. This kind of absorption is due to the precipitation of energetic electrons (energy range from 10 to $100 \mathrm{KeV}$ ) in the E-region and upper D-region ( 70-100 km) (Kellerman 2009).

While comparing the two events, we observed higher CNA for the storm-time substorm event. 
During storm-time substorm, the southward turning of IMF $\mathrm{Bz}$ occurred at around $0500 \mathrm{UT}$ and was sustained up to $6 \mathrm{hrs}$. Moreover, the solar wind velocity $(\boldsymbol{v})$ was high $(\sim 550 \mathrm{~km})$ during the event. Thereby the convection electric field $(-V \times B z)$ was stronger $(5.5 \mathrm{mV} / \mathrm{m})$ and was sustained for longer period of time $(\sim 6 \mathrm{hrs})$ which we can infer from figure 5 . One thing to be noticed in this storm-time substorm event is the difference of $\sim 01 \mathrm{hr}$ between the southward turning of IMF Bz and onset of substorm. That means strengthening of convection electric field occurred much earlier $(\sim 01 \mathrm{hr})$ that drove more flux of energetic charge particles in to the magnetosphere and caused subsequent loading of particles into the magnetotail region before the reconnection occured. Whereas, the other event of non-storm time substorm (figure 6) clearly shows weaker convection electric field $(\sim 3.4 \mathrm{mV} / \mathrm{m})$ for lesser period of time ( $\sim 2 \mathrm{hrs}$ ). During this event the southward turning of IMF $\mathrm{Bz}$ occurred only $10 \mathrm{~min}$ before the onset of substorm and was sustained for comparatively less time $(\sim 2 \mathrm{hr})$ as compared to the storm-time substorm event. In addition to that, the solar wind velocity $(V)$ was also moderate $(\sim 340 \mathrm{~km})$ during this event. This clarifies that level of CNA is more related to loading of the particles and intensity of reconnection in the magnetotail. These results also strongly support the difference between storm-time substorm and non-storm time substorm characteristics stated by Hsu and McPherron (1998). They clearly mentioned in their paper in 1998 that the energy accumulation and the dipolarization tend to be more significant during storm time substorms. Moreover, the reconnection of higher intensity also triggered a moderate storm which was associated with the 12 April 2011 event.

Finally, we can conclude that depression in geomagnetic H-component and CNA at Maitri are the consequences of flux of electrons intensifying the auroral electrojet and precipitation of electrons enhancing the conductivity of the upper D-region respectively. The correlation coefficient between $\mathrm{H}$-component and CNA strength at Maitri is -0.88 for storm time substorm event and it is -0.53 for non-storm time substorm event. Correlation coefficient for both the events are significant as enough number of data points $(\sim 7200)$ have gone into the analysis. It is clear that CNA and $\mathrm{H}$-component of geomagnetic field variation correlate well for both the events. However, the extent of CNA depends on the strength of the magnetospheric convection electric field and the duration of southward IMF Bz before the substorm onset. Nevertheless, a proper statistical study may explore the possible empirical relationship between convection electric field and CNA at a subauroral station such as Maitri.

\section{Acknowledgements}

The authors are indebted to F Honary and group from Lancaster University for their invaluable help in installing of imaging riometer and preliminary data processing. The authors express their sincere thanks to National Centre for Antarctic \& Ocean Research (Ministry of Earth Sciences) for providing funds for purchase and installation of imaging riometer at Indian Antarctic station, Maitri and all the infrastructural facilities during the antarctic expeditions. The authors would also like to acknowledge the CDAWeb for providing ACE satellite data, World Data Centre (WDC), Kyoto for geomagnetic indices.

\section{References}

Abdu M A, Degaonkar S S and Ramanathan K R 1967 Attenuation of galactic noise at $25 \mathrm{MHz}$ and $21.3 \mathrm{MHz}$ in the ionosphere over Ahmedabad during 1957-1964; J. Geophys. Res. 72 1547-1554.

Aggrawal K M, Nath N and Setty C S G K 1979 Collision frequency and transport properties of electrons in the ionosphere; Planet. Space Sci. 27 753-786.

Allen J H and Kroehl H W 1975 Spatial and temporal distributions of magnetic effects of auroral electrojets as derived from AE indices; J. Geophys. Res. 80 3607-3677.

Ansari Z A 1964 The aurorally associated absorption of cosmic noise at college, Alaska; J. Geophys. Res. 69 4493-4513.

Armstrong R J, Berkey F T and Melbye T 1977 The day to night ratio in auroral zone riometer measurements; Planet. Space Sci. 25 1193-1198.

Baker D N, Pulkkinen T I, Angelopoulos V, Baumjohann W and McPherron R L 1996 Neutral line model of substorms: Past results and present view; J. Geophys. Res. 101 12,975-13,010

Baumjohan W, Kamide Y and Nakamura R 1996 Substorms, storms, and near-Earth tail; J. Geomagn. Geoelectr. 48 $177-185$.

Bhonsle R V and Ramanathan K R 1958 Studies of cosmic radio noise on $25 \mathrm{Mc} / \mathrm{s}$ at Ahmedabad; J. Sci. Ind. Res. 17A 40-45.

Browne S, Hargreaves J K and Honary B 1995 An imaging riometer for ionospheric studies; Electronics and Communication 7 209-217.

Butler J and Lowe R 1961 Beam-forming matrix simplifies design of electrically scanned antennas; Electronic Design 12 170-173.

Detrick D L and Rosenberg T J 1990 A phase-array radiowave imager for studies of cosmic noise absorption; Radio Sci. 25 325-338.

Frey H U, Mende S B, Angelopoulos V and Donovan E F 2004 Substorm onset observations by IMAGE-FUV; J. Geophys. Res. 109 A10304.

Hargreaves J K, Detrick D L and Rogenberg T J 1991 Spacetime structure of auroral abasorption events observed with the imaging riometer at South Pole; Radio Sci. 26 925-930.

Honary F, Marple S R, Barrath K, Chapman P, Grill M and Nielsen E 2011 Digital beam forming imaging riometer systems; Rev. Sci. Instrum. 82 0313011-13.

Hsu T-S and McPherron R L 1998 The main onset of a magnetospheric substorm; In: Proc. Int. Conf. Substorm 
(ICS-4), (eds) Kokubun S and Kamide Y, Terra Scientific Publishing Company, Tokyo, Lake Hamana, Japan, pp. 79-82.

Kellerman A C 2009 On the relationship between auroral absorption, electrojet currents and plasma convection; Ann. Geophys. 27 473-486.

Krishnaswamy S, Detrick D L and Rosenberg T 1985 The inflection point method of determining riometer quiet day curves; Radio Sci. 20 123-136.

Little C G and Leinbach H 1958 Some measurements of high latitude ionospheric absorption using extraterrestrial radio waves; Proc. IRE 46 334-348.

Little C G and Leinbach H 1959 The riometer - a device for continues measurement of ionospheric absorption; Proc. IRE 47 315-320.

Little C G 1954 High latitude ionospheric observations using extra terrestrial radio waves; Proc. IRE 421700.

Lui A T Y, Lopez R E, Krimigis S M, McEntire R W, Zanetii L J and Potemra T A 1998 A case study of magnetotail current sheet disruption and diversion; Geophys. Res. Lett. 15(7) 721-724.

Lunetta M and Abdu M A 1971 A study on the latitudinal features of the ionospheric absorption excursion; Revista Brasileira de Física 1 369-379.

Lusignan B 1960 Cosmic noise absorption measurements at Stanford, California, and Pullman, Washington; J. Geophys. Res. 65 3895-3902.

Mailloux R J 2005 Phased Array Antenna Handbook, 2nd edn, Artech House, Boston.

Mitra A P and Shain C A 1953 The measurement of ionospheric absorption using observations of $18.3 \mathrm{Mc} / \mathrm{s}$ cosmic radio noise; J. Atmos. Terr. Phys. 4 204-218.

Moro J, Denardini C M, Correia E, Abdu M A, Schuch N J and Makita K 2012 A comparision of two different techniques for deriving the quiet day curve from SARINET riometer data; Ann. Geophys. 30 11591168.

Parameswaran K and Krishnamurthy B V 1976 Studies on ionospheric absorption by riometer technique at magnetic equator; Ann. Geophys. 32 419-427.

Rourke G F 1961 Minor PCA events during March 1958; J. Geophys. Res. 66 4316-4318.

Schlegel K and St-Maurice J P 1981 Anomalous heating of polar E region by unstable plasma waved: 1. Observatons; J. Geophys. Res. 86 1447-1452.

Sen H K and Wyller A A 1960 On the generalizations of Appleton-Hartree magnetoionic formulas; J. Geophys. Res. 65 3931-3950.

Singh A K, Sinha A K, Rawat R, Jayashree B, Pathan B M and Dhar A 2012 A broad climatology of very high latitude substorms; Adv. Space Res. 50 1512-1523.

St-Maurice J P, Schlegel K and Banks P M 1981 Anomalous heating of the polar E region by unstable plasma waves.2; Theory J. Geophys. Res. 86 1447-1452.

Stauning P 1994 Investigations of ionospheric radio wave absorption processes using imaging riometer techniques; Geophys. Res. Lett. 58 753-764.

Steiger W R and Warmick J W 1961 Observations of cosmic radio noise at $18 \mathrm{Mc} / \mathrm{s}$ in Hawaii; J. Geophys. Res. 66 57-66.

Tanaka Y, Makita K, Nishino M and Ookawa T 2007 Development of data analysis program for imaging riometer by using MATLAB; Takushoku University; Bull. Sci. Eng. 10 61-66.

Walker J K and Bhatnagar V P 1989 Ionospheric absorption, typical ionization, conductivity, and possible synoptic heating parameters in the upper atmosphere; J. Geophys. Res. 94 3713-3720. 